\title{
New p22-Phox Monoclonal Antibodies: Identification of a Conformational Probe for Cytochrome $b_{558}$
}

\author{
Yannick Campion ${ }^{a}$ Algirdas J. Jesaitis ${ }^{c}$ Minh Vu Chuong Nguyen ${ }^{a}$ \\ Alexei Grichine $^{b}$ Yvan Herenger ${ }^{a} \quad$ Athan Baillet $^{a}$ Sylvie Berthier ${ }^{a}$ \\ Françoise Morel $^{\mathrm{a}} \quad$ Marie-Hélène Paclet ${ }^{\mathrm{a}}$ \\ aGREPI, TIMC-Imag UMR 5525 CNRS/Université Joseph Fourier, Laboratoire d'Enzymologie, CHU Grenoble, \\ Grenoble, and 'Platform 'Optical Microscopy - Cell Imaging' - UJF, Inserm U823, Institut Albert Bonniot, \\ La Tronche, France; 'Department of Microbiology, Montana State University, Bozeman, Mont., USA
}

\section{Key Words}

Cytochrome $b_{558} \cdot$ p22-phox conformation $\cdot$ Monoclonal antibody $\cdot$ Phagocyte NADPH oxidase $\cdot$ Nox

\begin{abstract}
The phagocyte NADPH oxidase, belonging to the NADPH oxidase family (Nox), is dedicated to the production of bactericidal reactive oxygen species. The enzyme catalytic center is the cytochrome $b_{558}$, formed by 2 subunits, Nox2 (gp91phox) and p22-phox. Cytochrome $b_{558}$ activation results from a conformational change induced by cytosolic regulatory proteins (p67-phox, p47-phox, p40-phox and Rac). The catalytic subunit is Nox2, while p22-phox is essential for both Nox2 maturation and the membrane anchorage of regulatory proteins. Moreover, it has been shown to be necessary for novel Nox activity. In order to characterize both p22-phox topology and cytochrome $b_{558}$ conformational change, 6 monoclonal antibodies were produced against purified cytochrome $b_{558}$. Phage display epitope mapping combined with a truncation analysis of recombinant p22-phox allowed the identification of epitope regions. Some of these antibodies almost completely inhibited in vitro reconstituted NADPH oxidase activity. Data analysis identified antibodies that rec-
\end{abstract}

ognized epitopes involved in either Nox2 maturation or Nox2 activation. Moreover, flow cytometry analysis and confocal microscopy performed on stimulated neutrophils showed that the monoclonal antibody $12 \mathrm{E} 6$ bound preferentially active cytochrome $b_{558}$. These monoclonal antibodies provided novel and unique probes to investigate maturation, activation and activity, not only of Nox2 but also of novel Nox.

Copyright $\odot 2009$ S. Karger AG, Basel

\section{Introduction}

Neutrophil cytochrome $b_{558}$ is a membrane heterodimer composed of Nox2 (gp91-phox) and p22-phox. This is the catalytic center of the phagocyte NADPH oxidase complex responsible for the production of reactive oxygen species in response to inflammatory stimuli $[1,2]$. The NADPH oxidase is a multisubunit enzyme complex which is inactive and compartmentalized between cytosol and membrane in resting neutrophils. In stimulated cells, cytosolic regulatory proteins (p47-phox, p67-phox, p40-phox and the monomeric $G$ protein Rac) translocate to the membrane cytochrome $b_{558}$, inducing a cyto-

\section{KARGER}

(C) 2009 S. Karger AG, Basel

Fax +41613061234

E-Mail karger@karger.ch

www.karger.com
Dr. Marie-Hélène Paclet

GREPI, TIMC-Imag UMR 5525, Laboratoire d'Enzymologie

Université Joseph Fourier/DBPC, CHU Grenoble

BP 217, FR-38043 Grenoble Cedex 9 (France)

Tel. +33 4767654 83, Fax +33 4767656 08, E-Mail MHPaclet@chu-grenoble.fr 
chrome $b_{558}$ conformational change and electron transfer from the NADPH to the molecular oxygen. Resulting superoxide anion radicals are precursors for various toxic oxygen metabolites implicated in the defense against pathogens [1-6]. A defect in NADPH oxidase activity causes chronic granulomatous disease (CGD), a rare genetic disorder characterized by severe and recurrent infections due to the inability of phagocytes to contribute to the killing of microorganisms $[7,8]$.

The structure of cytochrome $b_{558}$ has not yet been solved. Computational analysis of primary sequence of Nox2 and p22-phox suggests that both subunits contain transmembrane domains ( 6 and $2-4$, respectively). The cytochrome $b_{558}$ catalytic subunit is Nox2. It binds $\mathrm{NADPH}$ and flavin adenine dinucleotide in the last 280 residues of its C-terminal tail and possesses 4 histidine residues that coordinate 2 hemes involved in the last electron transfer step leading to the production of superoxide anions [9]. Even though no catalytic activity has been described for p22-phox, it is an essential component of cytochrome $b_{558}$, as its absence in myeloid cells leads to the degradation of Nox 2 . It has been previously shown that the incorporation of hemes was required for both the p22-phox/Nox 2 dimer formation in the endoplasmic reticulum and the maturation of cytochrome $b_{558}$ [10]. The p22-phox subunit has 2 major functions. It binds and stabilizes Nox proteins, and serves as a membrane anchor for cytosolic regulatory factors. It was recently shown that p22-phox also associates with Nox1, Nox3 and Nox4 $[11,12]$, suggesting a central role of p22-phox in the cellular production of reactive oxygen species.

At the moment, the topology and functional domains within p22-phox are not clearly characterized. P22-phox was proposed to contain 2-4 membrane-spanning segments according to the primary sequence analysis by computational methods [13]. However, experimental evidence obtained with both specific antibodies directed against the cytosolic parts of p22-phox and cytochrome $b_{558}$ proteolytic digestion [13] suggest (1) the presence of 2 transmembrane domains and (2) the cy tosolic localization of the $\mathrm{N}$ - and $\mathrm{C}$-terminal regions of the protein. The C-terminal tail of p22-phox contains a proline-rich region involved in interactions with $\mathrm{SH} 3$ domains of $\mathrm{p} 47$ phox and also p67-phox [14, 15]. Phage display epitope mapping of specific monoclonal antibodies (mAbs) has identified 2 tertiary structures within the cytosolic parts of p22-phox. The first is composed of residues ${ }^{29} \mathrm{TAGRF}^{33}$ and ${ }^{183} \mathrm{PQVNPI}{ }^{188}$ corresponding to the $\mathrm{mAb} 44.1$ epitope, and the second is composed of ${ }^{51}{ }^{2 L E Y P R G}{ }^{57}$ and ${ }^{77}$ VKLFGP $^{82}$ corresponding to the mAb NS5 [13].
In the present study, we report the production and characterization of 6 novel mAbs (12E6, 17A2, 16G7, 16G6, 13D4 and 13C4) obtained after injection of a mixture of cytochrome $b_{558}$ purified from resting and PMAstimulated neutrophils. These novel mAbs were epitope mapped by phage display analysis and were shown to recognize various regions in the C-terminal domain of $\mathrm{p} 22$ phox. These mAbs displayed different and specific properties with regard to their ability to detect native and/or denatured p22-phox and their capacity to inhibit the production of superoxide in vitro. Moreover, mAb 12E6 bound a conformational epitope localized in the polyproline region of p22-phox. Interestingly, it better recognized cytochrome $b_{558}$ in its active form, suggesting that the target epitope was unmasked during activation. Information resulting from a computational analysis of phage display, results by the program FINDMAP and a visual comparison of phage display sequences and the gp91phox sequence suggest a potential complex epitope for $\mathrm{mAb} 12 \mathrm{E} 6$ shared between $\mathrm{p} 22$-phox and Nox2. These $\mathrm{mAbs}$ provide novel and unique probes for investigation of the maturation, activation and activity, not only of cytochrome $b_{558}$ but also of novel Nox.

\section{Materials and Methods}

\section{Materials}

Chemical reagents used in this study were obtained from the following sources: enhanced chemiluminescence (ECL) Western blotting detection reagents (Amersham Pharmacia Biotech, Uppsala, Sweden); PMA, arachidonic acid (Sigma Chemicals, St. Louis, Mo., USA); n-octyl glucoside (Roche Diagnostics, Meylan, France); Alexa Fluor ${ }^{\circledR} 488 \mathrm{~F}\left(\mathrm{ab}^{\prime}\right)_{2}$ fragment of goat anti-mouse IgG $(\mathrm{H}+\mathrm{L})$ (Molecular Probes Europe BV, Leiden, The Netherlands); Goat $\mathrm{F}\left(\mathrm{ab}^{\prime}\right)_{2}$ fragment anti-mouse IgG $(\mathrm{H}+\mathrm{L})$-phycoerythrin (Immunotech-Beckman Coulter, Marseille, France); horseradish peroxidase-conjugated rabbit anti-mouse IgG ( $\gamma$-specific) (Open Biosystems, Huntsville, Ala., USA); pCDNA3.1-V5/HisB (Invitrogen, Cergy Pontoise, France).

\section{Purification of Cytochrome $\mathrm{b}_{558}$ from Resting or Stimulated}

Neutrophils

Cytochrome $b_{558}$ was purified from the plasma membranes of $10^{10}$ resting or PMA-stimulated neutrophils after 3 chromatographic steps (ion exchange, heparin-agarose and Sephacryl S300) as previously described [16]. The purified cytochrome $b_{558}$ solubilized in $0.1 \%(\mathrm{w} / \mathrm{v})$ Triton X-100 buffer was quantified by the reduced minus oxidized difference spectra using an absorption coefficient of $106 \mathrm{~mm}^{-1} \mathrm{~cm}^{-1}$ for the Soret band at $426 \mathrm{~nm}$ [16].

Production of $m A$ bs to Cytochrome $\mathrm{b}_{558}$

Mice immunization and $\mathrm{mAb}$ production were performed by the 'BET analyses' company (Marseille, France) and Biotem company (Le Rivier d'Apprieu, France), respectively. Briefly, Balb/c 
mice were immunized by 3 intraperitoneal injections (interval of 14 days) of a mixture of $15 \mu \mathrm{g}$ cytochrome $b_{558}$ purified from resting neutrophils $(306 \mu \mathrm{l})$ and $15 \mu \mathrm{g}$ cytochrome $b_{558}$ purified from PMA-stimulated neutrophils $(158 \mu \mathrm{l})$ diluted with 1 volume of Freund's complete adjuvant $(464 \mu \mathrm{l})$. Antigens were solubilized in $0.1 \%(\mathrm{w} / \mathrm{v})$ Triton X-100 [17]. Resulting mAbs were purified from ascitic fluid after isotype identification (Dr. J. C. Renversez, DBI, CHU Grenoble, France). The isotype for 16G7, 12E6 and 13C4 was $\mathrm{IgG1}$, the isotype for 17A2 was IgG2a, the isotype for 16G6 was IgG2b and the isotype for 13D4 was IgM.

\section{Purification of Immunoglobulins from Ascitic Fluids}

Ascitic fluids were centrifuged at $10,000 \mathrm{~g}$ for $10 \mathrm{~min}$ at $4^{\circ} \mathrm{C}$. IgG were purified from the supernatant of centrifugation on protein A Sepharose. Depending on the Ig isotype, protein A Sepharose was equilibrated with either $50 \mathrm{~mm}$ sodium borate $\mathrm{pH} 8.9$ containing $3 \mathrm{M} \mathrm{NaCl}$ for IgG1 purification or $20 \mathrm{mM} \mathrm{Na}_{2} \mathrm{HPO}_{4}$ $\mathrm{pH} 7$ for IgG2 purification. After extensive washes with the equilibration buffer, IgG were eluted with $0.1 \mathrm{M}$ glycine $\mathrm{pH} 3$ [17]. Purified Ig were dialyzed against $\mathrm{PBS}$ and stored at $-20^{\circ} \mathrm{C}$. IgG purification was controlled by SDS-PAGE. IgM were purified by gel filtration on Sephacryl S-300 [18]. Purified antibodies (protein $1 \mathrm{mg} / \mathrm{ml}$ ) were dialyzed against PBS and stored at $-20^{\circ} \mathrm{C}$.

\section{Isolation of Human Neutrophils from Fresh Blood}

Human neutrophils were isolated from citrated venous blood of healthy volunteers after informed consent, diluted twice in PBS (137 mM NaCl, $2.7 \mathrm{mM} \mathrm{KCl}, 1.5 \mathrm{mM} \mathrm{KH}_{2} \mathrm{PO}_{4}, 8 \mathrm{mM} \mathrm{Na}_{2} \mathrm{HPO}_{4} \mathrm{pH}$ 7.3) containing $1 \%(\mathrm{w} / \mathrm{v})$ tri-sodium citrate, using a $33 \%(\mathrm{v} / \mathrm{v})$ Hypaque-Ficoll gradient. After 20 min centrifugation at $800 \mathrm{~g}$ at $20^{\circ} \mathrm{C}$, the pellet was submitted to a hypotonic lysis for 5-15 min on ice. After $5 \mathrm{~min}$ centrifugation at $350 \mathrm{~g}$ at $4^{\circ} \mathrm{C}$, the neutrophil pellet was collected and washed once in PBS [17].

\section{Triton X-100 Soluble Extract from Control and X91 ${ }^{\circ} \mathrm{CGD}$}

Neutrophils

Neutrophils from healthy donors and X91 ${ }^{0}$ CGD patients $\left(10^{7}\right.$ cells) were suspended in $100 \mu \mathrm{l}$ of Triton X-100 lysis buffer (3.5 $\mathrm{mM} \mathrm{MgCl}_{2}, 1 \%$ (w/v) Triton X-100, 10 mM Hepes $\mathrm{pH}$ 7.4) containing a mixture of protease inhibitors $(1.8 \mu \mathrm{M}$ leupeptin, $1.5 \mu \mathrm{M}$ pepstatin) and incubated for $20 \mathrm{~min}$ on ice. Then the mixture was centrifuged at $12,000 \mathrm{~g}$ for $30 \mathrm{~min}$ at $4^{\circ} \mathrm{C}$. The supernatant corresponding to the Triton $\mathrm{X}-100$ soluble extract was collected and stored at $-80^{\circ} \mathrm{C}$ until further use [17].

\section{Neutrophil Stimulation by PMA}

Purified neutrophils $\left(5 \times 10^{6}\right.$ cells $\left./ \mathrm{ml}\right)$ were stimulated by PMA [ $130 \mathrm{nM}$ in $0.05 \%(\mathrm{v} / \mathrm{v}) \mathrm{DMSO}$ ] for $10 \mathrm{~min}$ at $37^{\circ} \mathrm{C}$. A control experiment was performed by incubating cells with $0.05 \%(\mathrm{v} / \mathrm{v})$ DMSO alone for $10 \mathrm{~min}$ at $37^{\circ} \mathrm{C}$. The reaction was stopped by adding ice-cold PBS. Cells were centrifuged at $350 \mathrm{~g}$ for $8 \mathrm{~min}$ at $4^{\circ} \mathrm{C}$ and resuspended in PBS for flow cytometry analysis or confocal microscopy.

\section{Flow Cytometry}

Purified neutrophils resuspended in PBS $\left(10^{7}\right.$ cells $\left./ \mathrm{ml}\right)$ were fixed with $1 \%(\mathrm{w} / \mathrm{v})$ paraformaldehyde for $15 \mathrm{~min}$ on ice. Cells were washed once with PBS and then resuspended at the concentration of $10^{7}$ cells $/ \mathrm{ml}$ in $\mathrm{PBS} / \mathrm{BSA} / \mathrm{CaCl} 2$ [PBS containing $0.2 \%$ (w/v) BSA and $0.5 \mathrm{mM} \mathrm{CaCl}_{2}$ ] containing $0.01 \%(\mathrm{w} / \mathrm{v})$ saponin for the solubilization. Incubation was performed for $10 \mathrm{~min}$ on ice. Cells $\left(5 \times 10^{5}\right)$ were then incubated on ice for $30 \mathrm{~min}$ with $5 \mu \mathrm{g}$ of mouse monoclonal Ig (irrelevant IgG or specific IgG) diluted in $100 \mu \mathrm{l}$ of $\mathrm{PBS} / \mathrm{BSA} / \mathrm{CaCl}_{2}$ buffer containing $0.01 \%$ (w/v) saponin [19]. Cells were washed twice in $500 \mu \mathrm{l}$ of $\mathrm{PBS} / \mathrm{BSA} / \mathrm{CaCl}_{2}$ buffer containing $0.01 \%(\mathrm{w} / \mathrm{v})$ saponin and resuspended in $150 \mu \mathrm{l}$ of the phycoerythrin-conjugated goat anti-mouse antibody diluted 1: 200 in $\mathrm{PBS} / \mathrm{BSA} / \mathrm{CaCl}_{2}$ buffer containing $0.01 \%$ (w/v) saponin. After $30 \mathrm{~min}$ incubation on ice, cells were washed twice with $500 \mu \mathrm{PBS} / \mathrm{BSA} / \mathrm{CaCl}_{2}$ buffer containing $0.01 \%$ (w/v) saponin before being resuspended in $500 \mu \mathrm{l}$ of $\mathrm{PBS} / \mathrm{BSA} / \mathrm{CaCl}_{2}$. Fluorescence intensity (FL2) of the phycoerythrin-labeled polymorphonuclear neutrophils was measured on a FACScalibur (Becton Dickinson) cytometer [19].

\section{Immunoprecipitation Experiments}

Neutrophil membranes were prepared as described previously [20]. Crude membrane proteins were adjusted at a concentration between 2 and $3 \mathrm{mg}$ protein/ml in $100 \mathrm{mM}$ Hepes $\mathrm{pH}$ 7.2, containing $100 \mathrm{~mm} \mathrm{KCl}, 10 \mathrm{mM} \mathrm{NaCl}, 1 \mathrm{mM}$ EDTA, 20\% (v/v) glycerol and the mixture of protease inhibitors $(1.8 \mu \mathrm{M}$ leupeptin, $1.5 \mu \mathrm{M}$ pepstatin, $10 \mu \mathrm{M}$ TLCK). Membrane proteins were then solubilized in presence of $68 \mathrm{mM} n$-octyl glucoside for $20 \mathrm{~min}$ on ice followed by centrifugation at $200,000 \mathrm{~g}$ for $1 \mathrm{~h}$ at $4^{\circ} \mathrm{C}$ (Rotor 50 Ti, Beckman L-60 ultracentrifuge) [20]. The resulting supernatant corresponded to the membrane soluble extract. Soluble extract $(200 \mu \mathrm{g})$ was diluted twice in PBS and incubated with protein $\mathrm{G}$ agarose $(40 \mu \mathrm{l})$ for $1 \mathrm{~h}$ at $4^{\circ} \mathrm{C}$ to remove nonspecific binding. The flow through was then incubated with $2 \mu \mathrm{g}$ specific $\mathrm{mAb}$ (12E6, 16G7 or 16G6) or irrelevant $\mathrm{mAb}$ for $4 \mathrm{~h}$ at $4^{\circ} \mathrm{C}$. Then protein $\mathrm{G}$ agarose was added to each sample for a further 1-hour incubation at $4^{\circ} \mathrm{C}$. After 3 washes with first PBS containing $0.5 \mathrm{M}$ $\mathrm{NaCl}$, then PBS with $0.1 \%$ Triton X-100 and finally PBS, the immunoprecipitates were solubilized in Laemmli buffer containing $5 \%(\mathrm{v} / \mathrm{v})$ mercaptoethanol [21] and analyzed by Western blot by using a secondary antibody directed against the heavy chain of $\mathrm{mAb}$ and coupled to peroxidase.

\section{Confocal Microscopy}

Purified neutrophils $\left(2 \times 10^{5}\right.$ cells in $50 \mu \mathrm{l}$ PBS $)$ were incubated on $0.01 \%(\mathrm{w} / \mathrm{v})$ poly-L-lysine-coated round glass cover slips for $15 \mathrm{~min}$ at $37^{\circ} \mathrm{C}$. After 2 washes with PBS, cells were fixed with $4 \%(\mathrm{w} / \mathrm{v})$ paraformaldehyde for $10 \mathrm{~min}$ at room temperature. Cover slips were rinsed twice with PBS and paraformaldehyde fluorescence was quenched by $50 \mathrm{mM} \mathrm{NH}_{4} \mathrm{Cl}$ for $10 \mathrm{~min}$ at room temperature. After 2 washes with PBS, cells were permeabilized with $0.1 \%(\mathrm{w} / \mathrm{v})$ Triton X-100 for $5 \mathrm{~min}$ at room temperature, followed by 2 washes with PBS. Then cells were incubated for $1 \mathrm{~h}$ at room temperature with $50 \mu$ l of mouse monoclonal Ig [p22-phox-specific Ig or irrelevant Ig; $5 \mu \mathrm{g}$ in $50 \mu \mathrm{l}$ PBS containing 1\% (w/v) BSA]. The cells were washed 3 times for 10 min with PBS containing $1 \%(\mathrm{w} / \mathrm{v})$ BSA prior to a 1-hour incubation with $100 \mu$ l of Alexa Fluor 488 donkey anti-mouse-Ig antibody [1: 500 in PBS containing $1 \%(w / v)$ BSA]. After 2 washes with PBS, cell nuclei were stained with $40 \mu \mathrm{l}$ Hoechst $33258(0.5 \mu \mathrm{g} / \mathrm{ml})$. Samples were then mounted in $10 \mu \mathrm{l}$ DABCO solution, sealed, and stored at $4^{\circ} \mathrm{C}$ in the dark. Fixed cells were imaged at room temperature using the inverted confocal and 2-photon laser-scanning microscope (LSM 510 NLO META; Carl Zeiss, Göttingen, Germany) equipped with a $40 \times / 1.3$ Plan-Neofluar oil immersion objective. The pinhole 
adjustment to 1 airy unit resulted in less than $0.7 \mu \mathrm{m}$ optical slice at $488 \mathrm{~nm}$ excitation wavelength. The image plane was chosen to be near the equator of the cell body and nucleus. The Alexa Fluor 488 fluorescence was selected with NFT490 dichroic beamsplitter and LP505 long-pass filter. The Hoechst 33258 fluorescence was excited by 2-photon absorption of the $720-\mathrm{nm}$ radiation of $\mathrm{fs} \mathrm{Ti}$ : Sa laser (Tsunami; Spectra-Physics GmbH, Darmstadt, Germany) and selected with 390-465 nm emission band-pass filter. No significant photobleaching was induced during image acquisition in either detection channel.

Generation of a Recombinant Plasmid for the Expression of a p22-Phox-Truncated Protein Coupled to eGFP

pCDNA3.1-V5/HisB was used to express p22 ( $\left.{ }^{1} \mathrm{M}-\mathrm{Q}^{143}\right)-\mathrm{GFP}$, a human $\mathrm{p} 22$-phox-truncated protein corresponding to amino acids ${ }^{1} \mathrm{M}$ to ${ }^{143} \mathrm{Q}$ fused with eGFP at the C-terminal part. Firstly, full-length eGFP was amplified with Pfu polymerase from the pTT3/eGFP plasmid with the following primers: $5^{\prime}$-GTTTCTCGAGATGATCGATGTGAGCAAGGGCGAGGAG-3' and ${ }^{\prime}$ GTTTGGGCCCTCACTTGTACAGCTCGTCCATGCCG-3'. The nucleotides corresponding, respectively, to the restriction sites XhoI and ApaI are underlined. The purified PCR product was digested with $X h o I$ and $A p a I$ and ligated into linearized pCDNA3.1-V5/HisB vector to obtain the pCDNA/eGFP plasmid. Secondly, PCR fragments corresponding to the p22(1-143)-truncated form were obtained by using $\mathrm{pEF} / \mathrm{p} 22$ phox plasmid as matrix with the forward primer 5'-GTTTGGTACCGCGGCCGCATGGGGCAGATCGAGTG-3' including a KpnI site (underlined) and the reverse primer 5'-CAAACTCGAGCTGCGGCCGCTCC-3'. The XhoI restriction site of the reverse primers is underlined. The purified PCR product was digested with KpnI and $X h o I$ and ligated into linearized pCDNA/eGFP plasmid to obtain a plasmid encoding a p22-phox-truncated protein fused with eGFP. All inserts were verified by sequencing (Genome Express, Grenoble, France) on an Abi Prism automatic sequencer (Perkin Elmer, Courtaboeuf, France).

\section{Stable Transfection of Mammalian Expression Plasmids}

HEK293E cells were trypsinized and counted; $4 \times 10^{5}$ HEK293E cells were seeded in 6-well plates and allowed to grow $24 \mathrm{~h}$ to reach a $60 \%$ confluence in $2 \mathrm{ml}$ of culture medium. The cells were transfected with $3 \mu \mathrm{g}$ of vectors according to the manufacturing protocol (JetPEI, Polyplus transfection). After $24 \mathrm{~h}$, stable transfected cells were selected with geneticin $500 \mu \mathrm{g} / \mathrm{ml}$ for 3 weeks before analysis. Membrane fractions of transfected cells were isolated as previously described for neutrophils [20].

\section{Reconstitution of NADPH Oxidase Activity}

Neutrophil membranes and cytosol for cell-free assays were prepared as described previously after cell sonication (3 times $10 \mathrm{~s}$ at $40 \mathrm{~W}$ ) and centrifugation at $1,000 \mathrm{~g}$ for $15 \mathrm{~min}$ at $4^{\circ} \mathrm{C}$. The supernatant was then centrifuged at $200,000 \mathrm{~g}$ for $1 \mathrm{~h}$ at $4^{\circ} \mathrm{C}$ to separate the cytosol (supernatant) and the crude membrane (pellet) [20]. Neutrophil membranes $(30 \mu \mathrm{g})$ were pre-incubated with p22-phox-specific or irrelevant $\mathrm{mAb}(50 \mu \mathrm{g})$ for $30 \mathrm{~min}$ on ice. Then neutrophil cytosol $(300 \mu \mathrm{g}), 40 \mu \mathrm{M}$ GTP $\gamma \mathrm{S}$ and $5 \mathrm{mM}$ $\mathrm{MgCl}_{2}$ were added to the membrane fraction in a final volume of $100 \mu \mathrm{l}$. An optimum amount of arachidonic acid (40-100 nmol) was used for activation [20]. After $10 \mathrm{~min}$ incubation at $25^{\circ} \mathrm{C}$, the medium was transferred to a photometric cuvette. The reaction was initiated by $150 \mu \mathrm{M}$ NADPH. Reconstituted oxidase activity was assessed by measuring the superoxide dismutase-sensitive portion of ferricytochrome $c$ reduction recorded at $550 \mathrm{~nm}$ (absorption coefficient at $550 \mathrm{~nm}: 21.1 \mathrm{~mm}^{-1} \mathrm{~cm}^{-1}$ ).

\section{Phage-Display Epitope Mapping}

The $6 \mathrm{mAbs}$ (17A2, 13C4, 13D4, 12E6, 16G6 and 16G7) were epitope mapped by selecting peptide sequences from the J404 nonapeptide library [22] by 3 successive rounds of affinity purification on antibodies covalently coupled to Sepharose followed by amplification on bacterial lawns on nutrient medium, as previously described [23]. After selection, high-affinity mAb-binding clones were identified after replica plating on nitrocellulose and immunoblot analysis, and then purified and sequenced. Sixteen to twenty nonapeptide sequences were obtained for the $6 \mathrm{mAbs}$ selections and were aligned visually as well as by the unique alignment algorithm used by the program FINDMAP [24].

\section{SDS-PAGE and Western Blotting}

Samples were loaded on a $10 \%$ or $11 \%$ SDS-PAGE [25] and electrotransferred to nitrocellulose, as previously described [26]. Immunodetection was performed using $\mathrm{mAbs}$ raised against $\mathrm{p} 22$ phox (mAb 44.1, 17A2, 13C4, 13D4, 12E6, $16 \mathrm{G} 6$ and 16G7; dilution $1: 1,000$ to $1: 5,000)$ or polyclonal antibody directed against the C-terminal part of p22-phox (residues 184-195; dilution $1: 1,000)$. The immune complexes were detected with a secondary antibody combined with peroxidase. The bound peroxidase activity was detected using ECL reagents.

Slot Blot Analysis of Purified Cytochrome $\mathrm{b}_{558}$

Cytochrome $b_{558}(10 \mathrm{pmol} /$ well $)$ purified from resting or PMAstimulated neutrophils was directly adsorbed on nitrocellulose under vacuum. The nitrocellulose was then saturated with $1 \%$ (w/v) low-fat milk proteins and immunodetection was performed using mAb 12E6 (dilution 1:1,000). Immune complexes were detected with a secondary antibody combined with peroxidase. The bound peroxidase activity was detected using ECL reagents.

\section{Results}

\section{Characterization of Six Novel Monoclonal Antibodies}

In order to further elucidate the topology of cytochrome $b_{558}, 6$ novel mAbs, named 17A2, 13C4, 13D4, 12E6, 16G6 and 16G7, were obtained after mouse immunization with cytochrome $b_{558}$ immunogens. The antigen consisted of a mixture of purified cytochrome $b_{558}$ fractions obtained from resting and PMA-stimulated neutrophils in $0.1 \%(\mathrm{w} / \mathrm{v})$ Triton X-100. These fractions had a specific activity in the range of $14-17 \mathrm{nmol}$ heme $b \cdot \mathrm{mg}$ protein $^{-1}$. The $6 \mathrm{mAbs}$ specifically recognized Triton X100 -solubilized $(0.1 \% \mathrm{w} / \mathrm{v})$ cytochrome $b_{558}$ purified either from resting or PMA-stimulated neutrophils by ELISA, suggesting that they bound the detergent solubilized protein (data not shown). To determine the subunit specificity of the mAbs, immunoblot analyses were performed 
Fig. 1. Western blot analysis with 6 novel cytochrome $b_{558}$ antibodies. Several neutrophil fractions were submitted to SDSPAGE followed by immunoblot identification: a Neutrophil cellular extracts $(40 \mu \mathrm{g} /$ well) from either $\mathrm{X}^{0} \mathrm{CGD}$ patient $\left(\mathrm{X}^{0}\right)$ or normal subject $(\mathrm{N})$, b neutrophil crude membrane (Mb: $30 \mu \mathrm{g} /$ well). The presence of gp91-phox was detected using the 6 novel mAbs (12E6, 17A2, 16G7, 16G6, 13D4 and 13C4) or control antibodies (mAb 44.1 or a polyclonal antibody, pAb, directed against the C-terminal peptide of $\mathrm{p} 22$ phox). The immune complexes were detected by ECL.

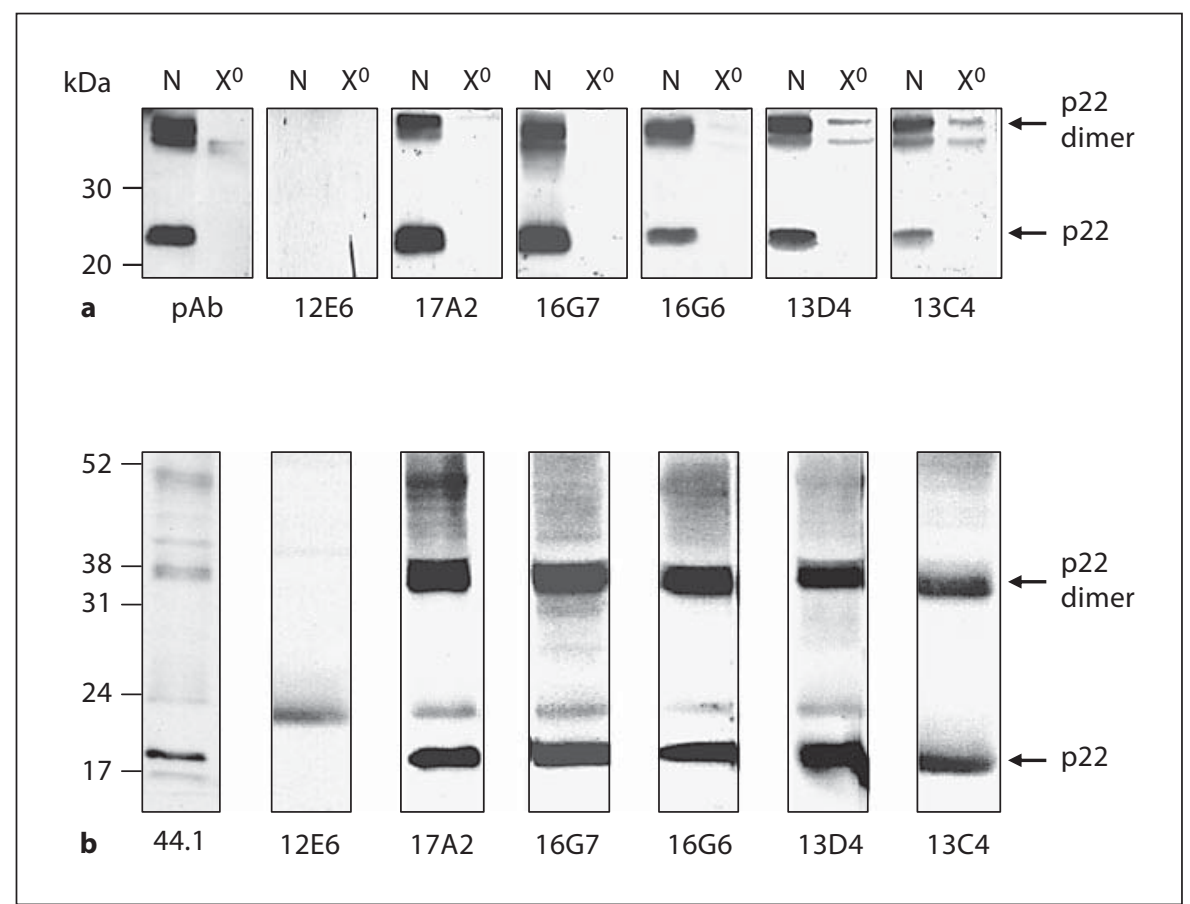

on Triton X-100-soluble extracts prepared either from control or from X91 ${ }^{\circ}$ CGD neutrophils (fig. 1a) as well as on neutrophil membrane fractions (fig. 1b). Two bands at approximately 24 and $44 \mathrm{kDa}$ were recognized by $5 \mathrm{mAbs}$ as well as by a control polyclonal antibody (fig. 1a). In contrast, these bands were not recognized in extracts from X91 ${ }^{\circ} \mathrm{CGD}$ neutrophils (fig. 1a), indicating that the bands corresponded to p22-phox and an aggregated dimer due to sample preparation. For mAb 12E6, no protein was detected by immunoblot, suggesting that this antibody recognized a conformational epitope on cytochrome $b_{558}$ (fig. 1). Similar results were obtained with purified cytochrome $b_{558}$ fractions (data not shown).

The binding of the $6 \mathrm{mAbs}$ to native antigen was further investigated by flow cytometry on both intact and saponin-permeabilized neutrophils. No mAb binding was observed on intact neutrophils (data not shown), while the $6 \mathrm{mAbs}$ bound strongly to permeabilized neutrophils like mAb 44.1, which is specific of a complex intracellular epitope formed by the regions ${ }^{29} \mathrm{TAGRF}^{33}$ and ${ }^{183}{ }^{P Q V N P I}{ }^{188}$ on p22-phox (fig. 2). Similar results were obtained with saponin-permeabilized EBV-B lymphocytes (data not shown). These data indicated that the 5 $\mathrm{mAbs}(17 \mathrm{~A} 2,13 \mathrm{C} 4,13 \mathrm{D} 4,16 \mathrm{G} 6$ and 16G7) recognized an intracellular epitope on p22-phox and that mAb $12 \mathrm{E} 6$ bound an intracellular region of cytochrome $b_{558}$ that does not survive SDS-PAGE.

\section{Determination of mAb Epitopes by Phage Display \\ Epitope Mapping}

In order to localize the $\mathrm{mAb}$ epitope regions, each $\mathrm{p} 22$ phox $\mathrm{mAb}$ was epitope mapped by phage display analysis. After immunopurification on $\mathrm{mAb}$ affinity matrices, the sequences of peptides interacting with each $\mathrm{mAb}$ were determined. Alignment of phage peptide sequences led to the identification of a consensus peptide sequence for 3 mAbs, 13D4, 16G7 and 12E6 (fig. 3, 4), while no clear consensus sequence was obtained for mAbs 16G6, 17A2 and $13 \mathrm{C} 4$. The consensus sequence was then compared with the primary structure of p22-phox. The resulting epitopes for the $3 \mathrm{mAbs}$ are shown in figures 3 and 4 . For both $\mathrm{mAb} 13 \mathrm{D} 4$ and $16 \mathrm{G} 7$, the epitope region was similar and corresponded to the ${ }^{130} \mathrm{QWTPIEPK}{ }^{137}$ region of $\mathrm{p} 22$ phox (fig. 3). However, the 16G7 epitope seemed to be longer than that of 13D4 (fig. 3b, 130-139 residues).

For mAb 12E6, which did not detect denatured cytochrome $b_{558}$ by immunoblot, a strong consensus sequence was determined 'GPRPPXPXP' (fig. 4a). This consensus demonstrated a high degree of similarity to the polyproline-containing region of p22-phox, ${ }^{159}{ }^{\mathrm{PRPPPNSP}}{ }^{152}$, suggesting that $\mathrm{mAb} 12 \mathrm{E} 6$ bound to $\mathrm{p} 22$-phox. In order to confirm that $\mathrm{mAb} 12 \mathrm{E} 6$ recognized $\mathrm{p} 22$-phox, immunoprecipitation of p22-phox with mAb12E6 was performed. An octyl-glucoside-soluble extract of neutrophil membrane was used for this assay. A similar experiment was 
Fig. 2. Flow cytometry analysis of cytochrome $b_{558}$ in permeabilized human neutrophils. Purified human neutrophils $(5 \times$ $10^{5}$ cells) were fixed with $1 \%(\mathrm{w} / \mathrm{v})$ paraformaldehyde, permeabilized with $0.01 \%$ $(\mathrm{w} / \mathrm{v})$ saponin and labeled with specific mAbs (12E6, 17A2, 16G7, 16G6, 13D4, 13C4 or 44.1; $5 \mu \mathrm{g}$; black area) or irrelevant $\mathrm{mAb}(5 \mu \mathrm{g}$; white area) for $30 \mathrm{~min}$ on ice. The antibody-labeled cells were stained with PE-conjugated secondary antibody, and the fluorescence (FL2) was measured.
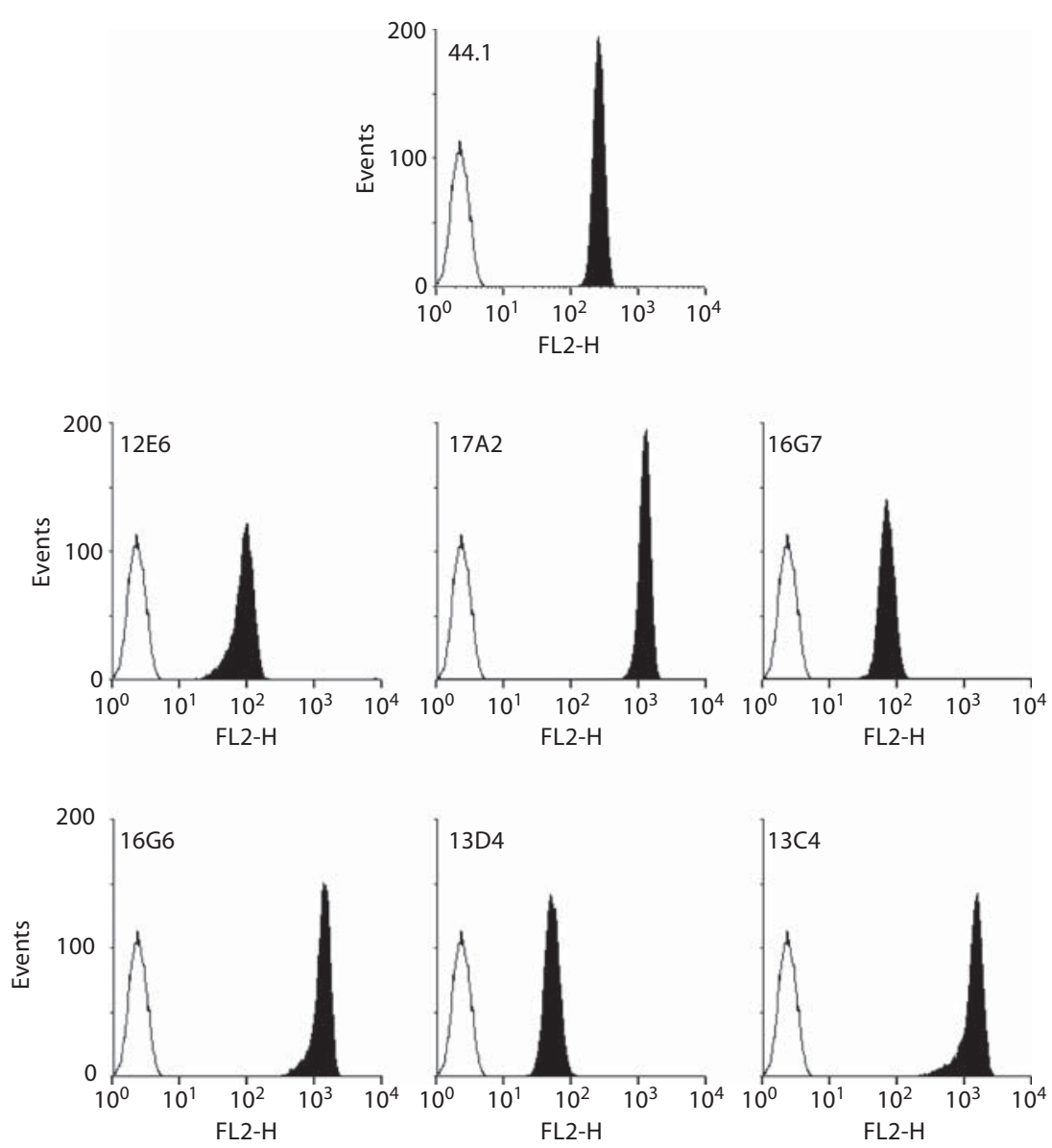

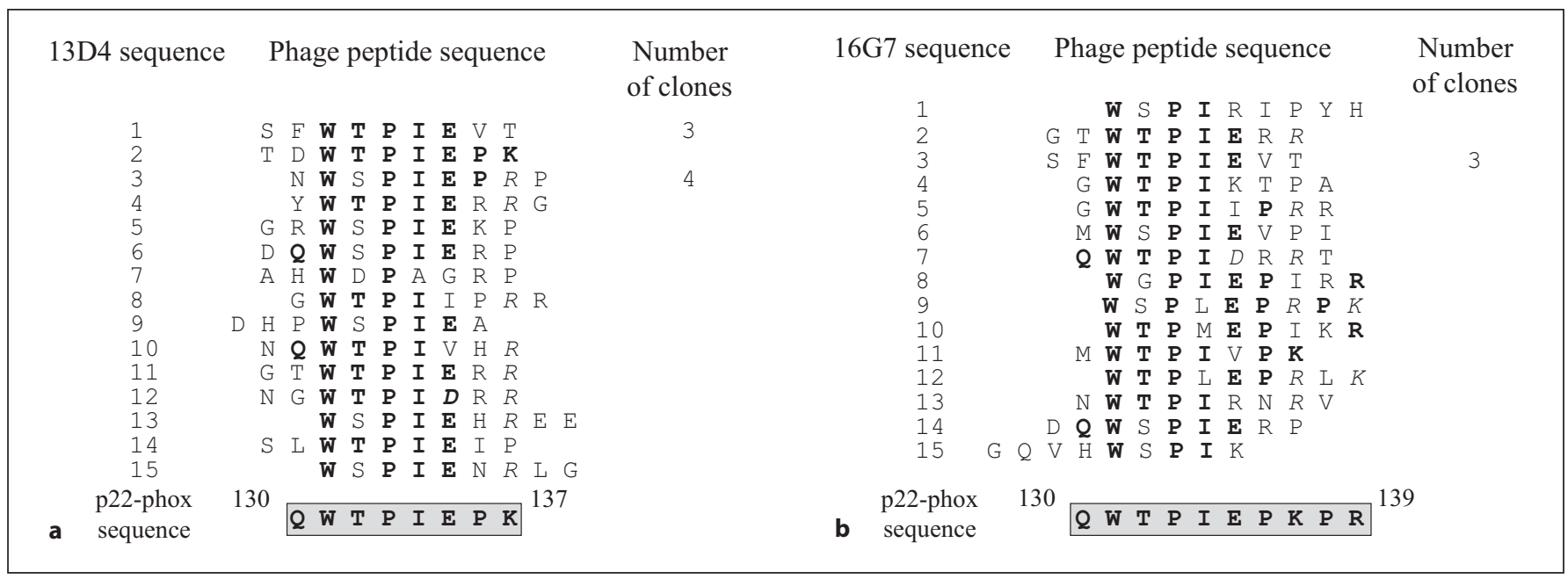

Fig. 3. Phage display epitope mapping for mAb 13D4 (a) and $\mathrm{mAb}$ 16G7 (b). After selection of phages on an mAb 13D4 (a) or mAb 16G7 (b) affinity matrix, the nucleotide sequence was determined on isolated phage clones. The corresponding peptide sequences were aligned to identify a consensus sequence, which was compared to p22-phox sequence in order to identify the epitope region. Residues of phage peptides identical to residues of p22-phox are in bold. The epitope sequence is framed. 
Fig. 4. Analysis of the mAb $12 \mathrm{E} 6$ interaction site. a Phage display epitope mapping for $\mathrm{mAb}$ 12E6 was performed as described in figure 3. The consensus sequence was compared to the primary structure of p22phox. Residues of phage peptides identical to residues of p22-phox are in bold. The potential epitope region is framed. b Immunoprecipitation studies with mAbs 12E6, 16G7 and 16G6. Cytochrome $b_{558}$ present in the membrane soluble extract $(200 \mu \mathrm{g})$ was immunoprecipitated with specific mAbs $(2 \mu \mathrm{g}$ of mAbs 12E6, 16G7 or 16G6) or irrelevant mAb. The filtrate (F) and the immunoprecipitate (IP) were submitted to SDS-PAGE followed by immunoblot identification of p22-phox with mAb 16G7. The immune complexes were detected by ECL.

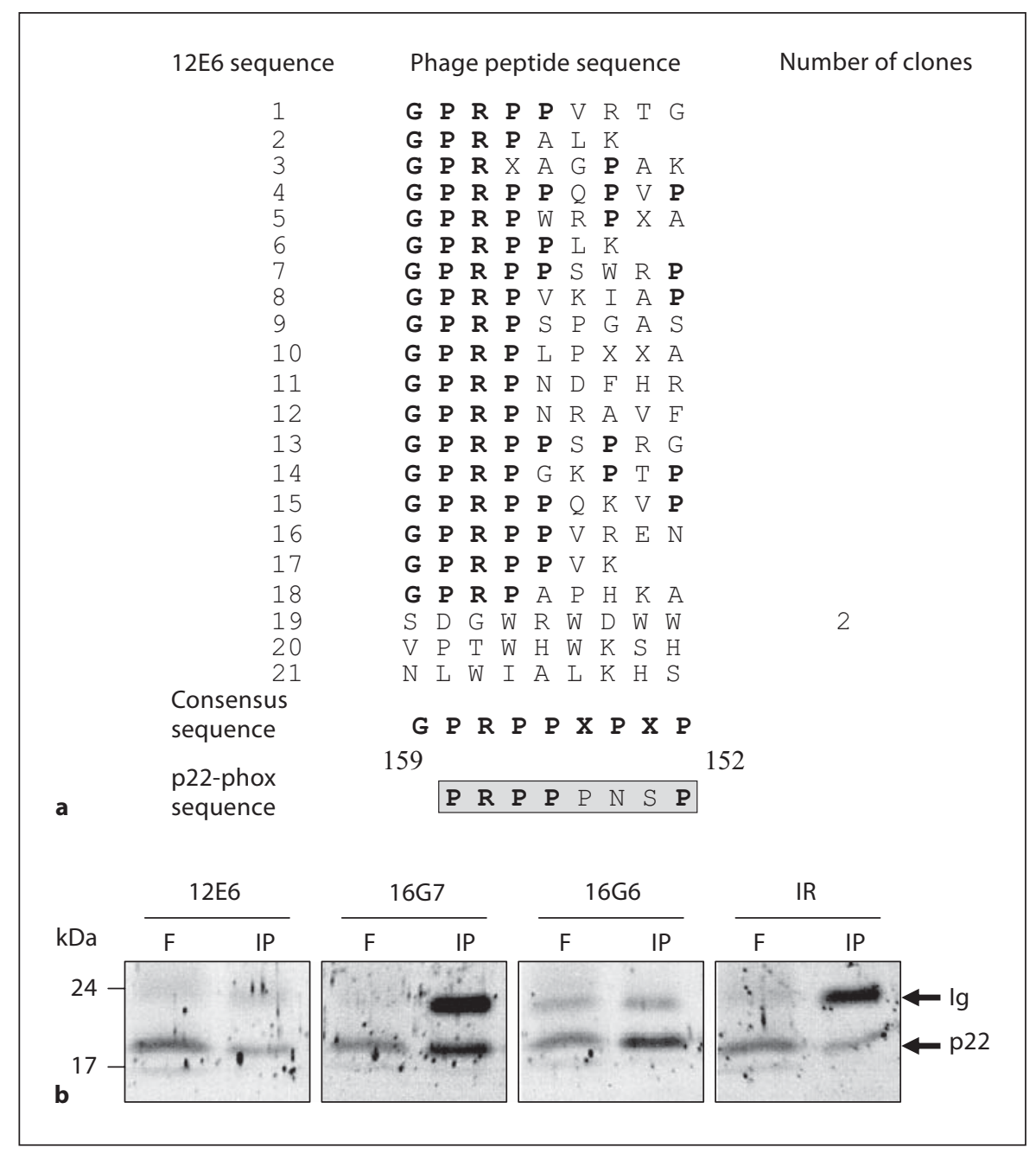

done with mAbs 16G7 and 16G6. Results showed that mAbs 16G6 and 16G7 were able to precipitate p22-phox. In contrast, no significant immunoprecipitation was observed with mAb12E6 as compared with the control performed with a nonspecific $\mathrm{mAb}$ (fig. $4 \mathrm{~b}$ ). This result suggested that recognition of the epitope by mAb12E6 was altered in octyl glucoside. Three possibilities could explain such a result: (1) the polyproline region of p22-phox could possess a three-dimensional structure modified during the solubilization process; (2) the 12E6 epitope could be a complex epitope implicating several regions of the cytochrome $b_{558}$; (3) the $12 \mathrm{E} 6$ was less effective in octyl glucoside.

To gain a more comprehensive understanding of the mAb12E6 epitope, an extensive analysis of the peptide sequences obtained by phage display was performed by using the computer program FINDMAP [24] in order to map the epitopes to discontinuous segments of the protein that are distant in the primary sequence, but are in close spatial proximity in the structure. This analysis was carried out on both gp91-phox and p22-phox sequences. Histograms presenting results confirmed a good matching of the $\mathrm{mAb} 12 \mathrm{E} 6$ consensus sequence on the polyproline region of p22-phox especially with the region ${ }^{155} \mathrm{PPPRPP}{ }^{160}$. Surprisingly, the analysis showed a strong match of a 3-residue segment of the consensus sequence with a short segment of the C-terminus of gp91-phox corresponding to residues ${ }^{557} \mathrm{GPR}^{559}$ (fig. 5).

\section{Confirmation of $m A b$ Epitope Regions by Using \\ Truncated Forms of p22-Phox}

In order to get more information about the regions recognized by these mAbs, a p22-phox-truncated form corresponding to amino acids $\left({ }^{1} \mathrm{M}-\mathrm{Q}^{143}\right)$ was expressed as 
Fig. 5. FINDMAP analysis for mAb 12E6. Alignment of phage sequences to discontinuous protein regions of $\mathrm{p} 22$ phox (a) or gp91-phox (b) by using the program FINDMAP [24]. Histograms presented the frequency of phage-peptide amino acids recovered in the target protein sequence. The potential epitope is presented in frame with amino acids belonging to both gp91phox and p22-phox.
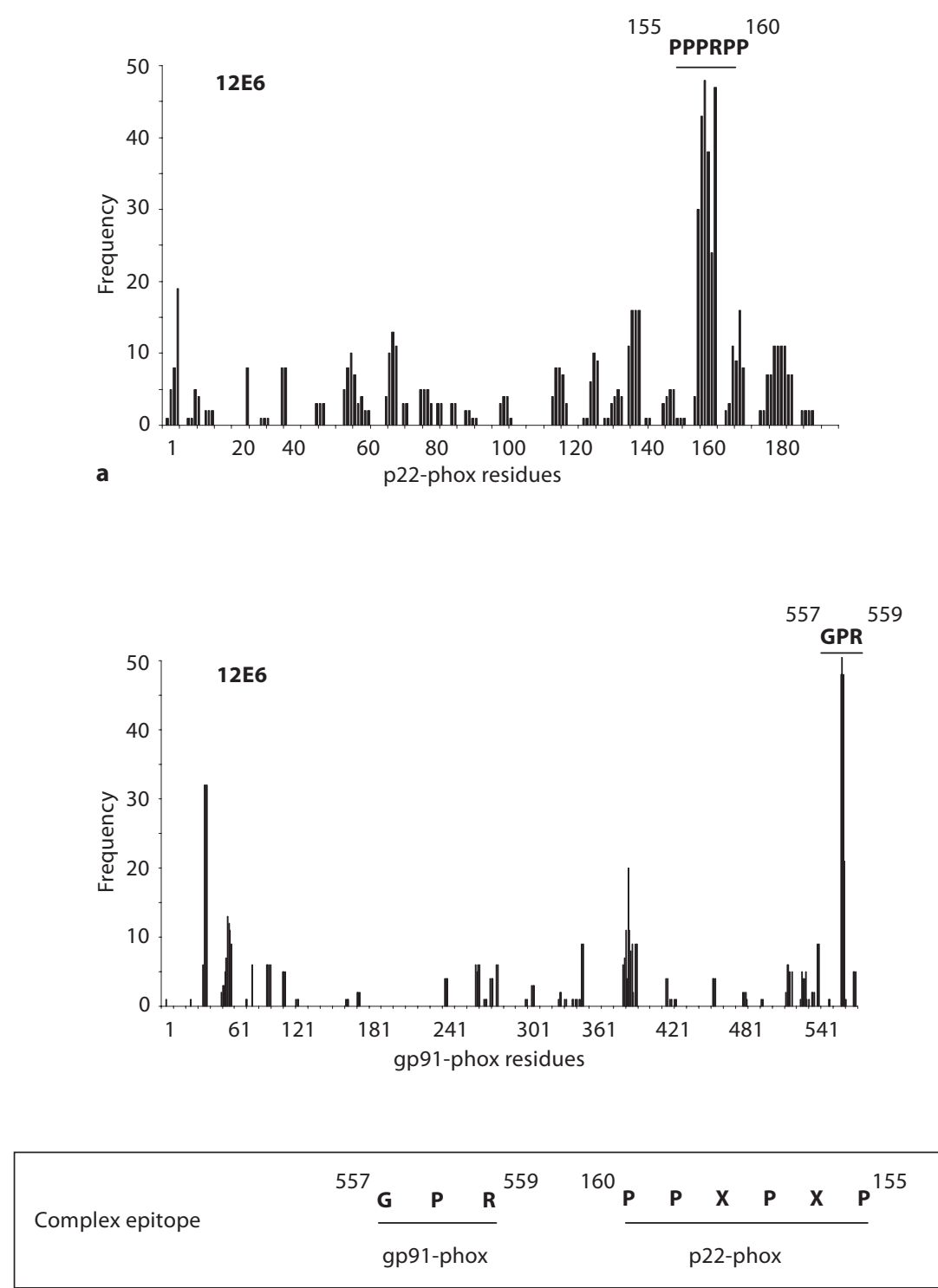

b a GFP-tagged protein in HEK293 cells (fig. 6a). To control the expression of the $\mathrm{p} 22\left({ }^{1} \mathrm{M}-\mathrm{Q}^{143}\right)$-GFP-truncated form, an immunoblot was performed on transfected HEK293 cells with an anti-GFP mAb (fig. 6b, left panel). Results showed a strong expression of the truncated form in the membrane of transfected HEK293 cells. Interestingly, only 2 p22-phox mAbs, 16G7 and 13D4, recognized the p22 $\left({ }^{1} \mathrm{M}-\mathrm{Q}^{143}\right)$-truncated form confirming the epitope determined by phage display. Absence of detection of the truncated form by the $3 \mathrm{mAbs} 17 \mathrm{~A} 2,16 \mathrm{G} 6$ and $13 \mathrm{C} 4$ in- dicated that they bound a region localized at the C-terminal part of p22-phox $\left({ }^{144} \mathrm{I}-\mathrm{V}^{195}\right)$. As observed with the full-length p22-phox, mAb 12E6 did not bind to the truncated form in Western blot analysis.

\section{Effect of $m A b$ anti-p22-Phox on the Phagocyte}

NADPH Oxidase Activation Process in vitro

In order to identify new specific Nox2 inhibitors, the effect of $\mathrm{mAbs}$ on the NADPH oxidase activity reconstituted in a homologous cell-free system was analyzed. In 


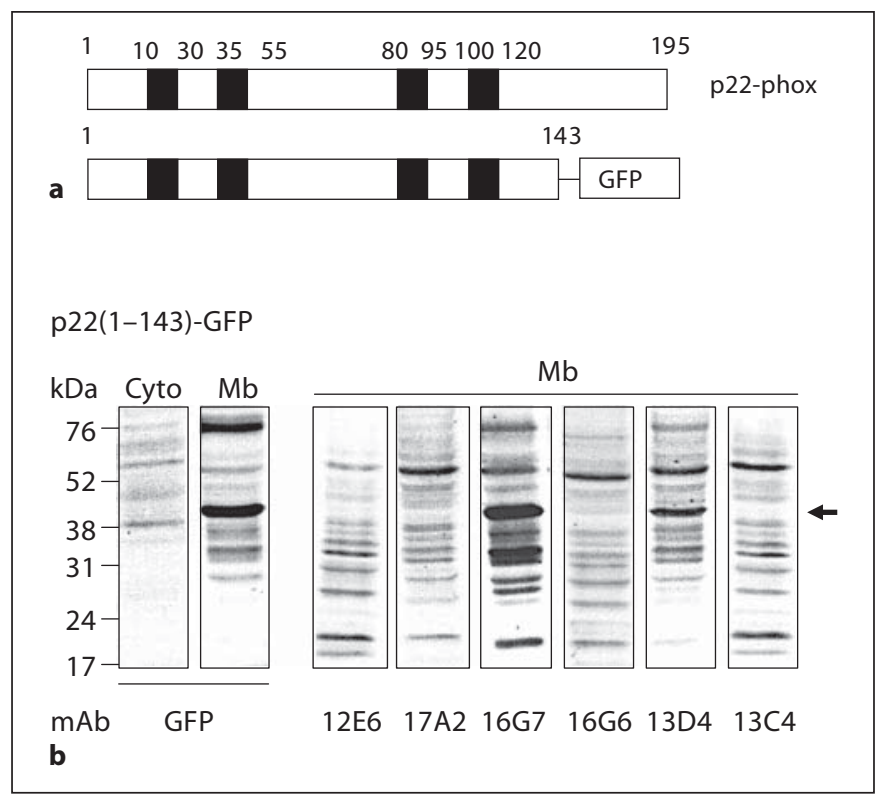

Fig. 6. Western blot of a p22-phox-truncated form. A truncated form of p22-phox corresponded to residues 1-143 [p22 $\left.\left({ }^{1} \mathrm{M}-\mathrm{Q}^{143}\right)\right]$ coupled to GFP at its C-terminus (a) was expressed in HEK293E cells. After geneticin selection, cells were isolated, fractioned into membrane and cytosol fractions and analyzed for their expression of the truncated p22-phox (b). Control of expression was performed with an anti-GFP mAb on both cytosolic (50 $\mu \mathrm{g}$ protein/ lane) and membrane (50 $\mu$ g protein/lane) fractions. A membrane fraction ( $50 \mu \mathrm{g}$ protein/lane) was analyzed by Western blot to evaluate the capacity of anti-p22-phox mAbs to bind truncated forms.

this experiment, neutrophil membranes were pre-incubated with a 37 -fold excess of $\mathrm{mAb}$ for $30 \mathrm{~min}$ on ice, before adding neutrophil cytosol and an optimal concentration of arachidonic acid (fig. 7). A control experiment was performed with an irrelevant antibody. In presence of $\mathrm{mAbs} 17 \mathrm{~A} 2,16 \mathrm{G} 7$ or 13D4 the production of superoxide was not altered. In contrast, the addition of $\mathrm{mAb}$ $12 \mathrm{E} 6,16 \mathrm{G} 6$ or $13 \mathrm{C} 4$ resulted in a strong inhibition of the reconstituted NADPH oxidase activity in the range of $65-80 \%$ compared to the activity measured in presence of an irrelevant $\mathrm{mAb}$. The $4 \mathrm{mAbs} 12 \mathrm{E} 6,17 \mathrm{~A} 2,16 \mathrm{G} 6$ and 13C4 recognized an epitope localized in the C-terminal region of p22-phox-containing residues $\left({ }^{144} \mathrm{I}-\mathrm{V}^{195}\right)$. Among these $4 \mathrm{mAbs}$, only mAb 17A2 did not inhibit the reconstituted NADPH oxidase activity, suggesting that the $\mathrm{mAb}$ 17A2 epitope was not located in domains involved in the interaction with cytosolic regulatory factors.

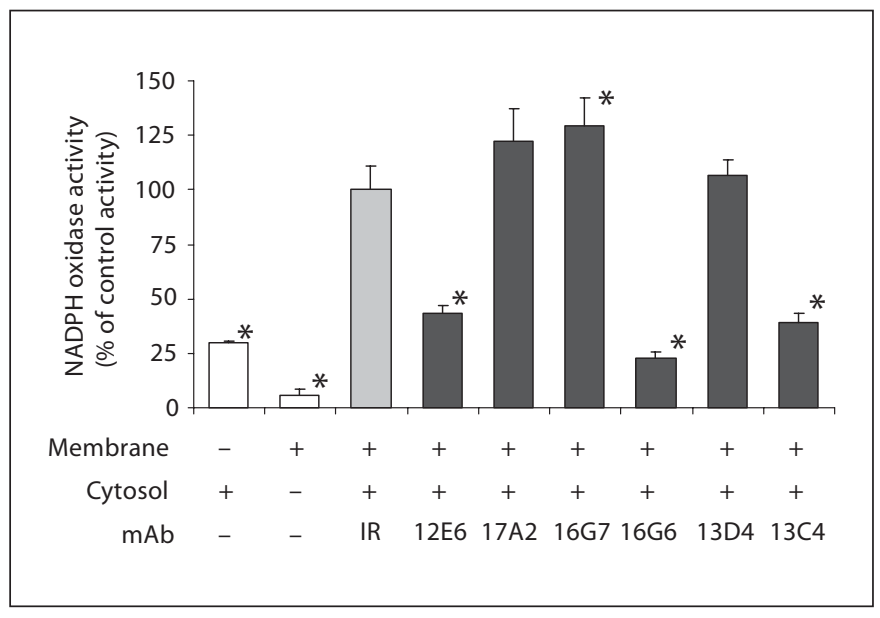

Fig. 7. Effect of the p22-phox mAbs on the NADPH oxidase activity reconstituted in a cell-free system. Neutrophil membrane fractions $(30 \mu \mathrm{g})$ were incubated with anti-p22-phox mAbs (12E6, 17A2, 16G7, 16G6, 13D4, 13C4; $50 \mu \mathrm{g}$ ), or an irrelevant mAb (IR; $50 \mu \mathrm{g}$ ) for $30 \mathrm{~min}$ on ice before adding neutrophil cytosol (300 $\mu \mathrm{g}), 40 \mu \mathrm{M}$ GTP $\gamma \mathrm{S}, 5 \mathrm{mM} \mathrm{MgCl}_{2}$ and an optimal concentration of arachidonic acid. The superoxide anion production was measured after addition of $150 \mu \mathrm{M}$ NADPH by the SOD-sensitive portion of the cytochrome $c$ reduction recorded at $550 \mathrm{~nm}$. Results were expressed as a percentage of the control activity obtained in the presence of an irrelevant $\mathrm{mAb}(100 \%$ corresponded to $168 \pm$ $18 \mathrm{nmol} \mathrm{O}=\mathrm{min}^{-1} \mathrm{mg}$ membrane protein ${ }^{-1}$ ). They were presented as the average of at least 3 experiments \pm SD. ${ }^{*} \mathrm{p}<0.05$ vs. presence of an irrelevant $\mathrm{mAb}$.

\section{Immunological Analysis of the Phagocyte NADPH \\ Oxidase Activation Process}

In our study, mAbs were produced against a mixture of cytochrome $b_{558}$ purified from resting and PMA-stimulated neutrophils. We analyzed the binding of $\mathrm{mAbs}$ to permeabilized neutrophils before and after stimulation with $130 \mathrm{nM}$ PMA for $10 \mathrm{~min}$ at $37^{\circ} \mathrm{C}$ by confocal microscopy (fig. 8). Control experiments were done in absence of the primary antibody or in presence of an irrelevant antibody. No significant fluorescence was detected in both cases (data not shown). Image acquisition on control, resting and PMA-stimulated cells was performed with exactly the same configuration settings of the confocal microscope in order to allow the qualitative comparison of the fluorescence intensities. Confocal microscopy done on resting cells with the $6 \mathrm{mAbs}$ showed a green fluorescence inside cells (fig. 8a, left panels). After PMA stimulation, the fluorescence signal intensity was not modified in cells stained with mAbs 17A2, 16G7, $16 \mathrm{G} 6,13 \mathrm{D} 4$ and $13 \mathrm{C} 4$. In contrast, the mean fluorescence 


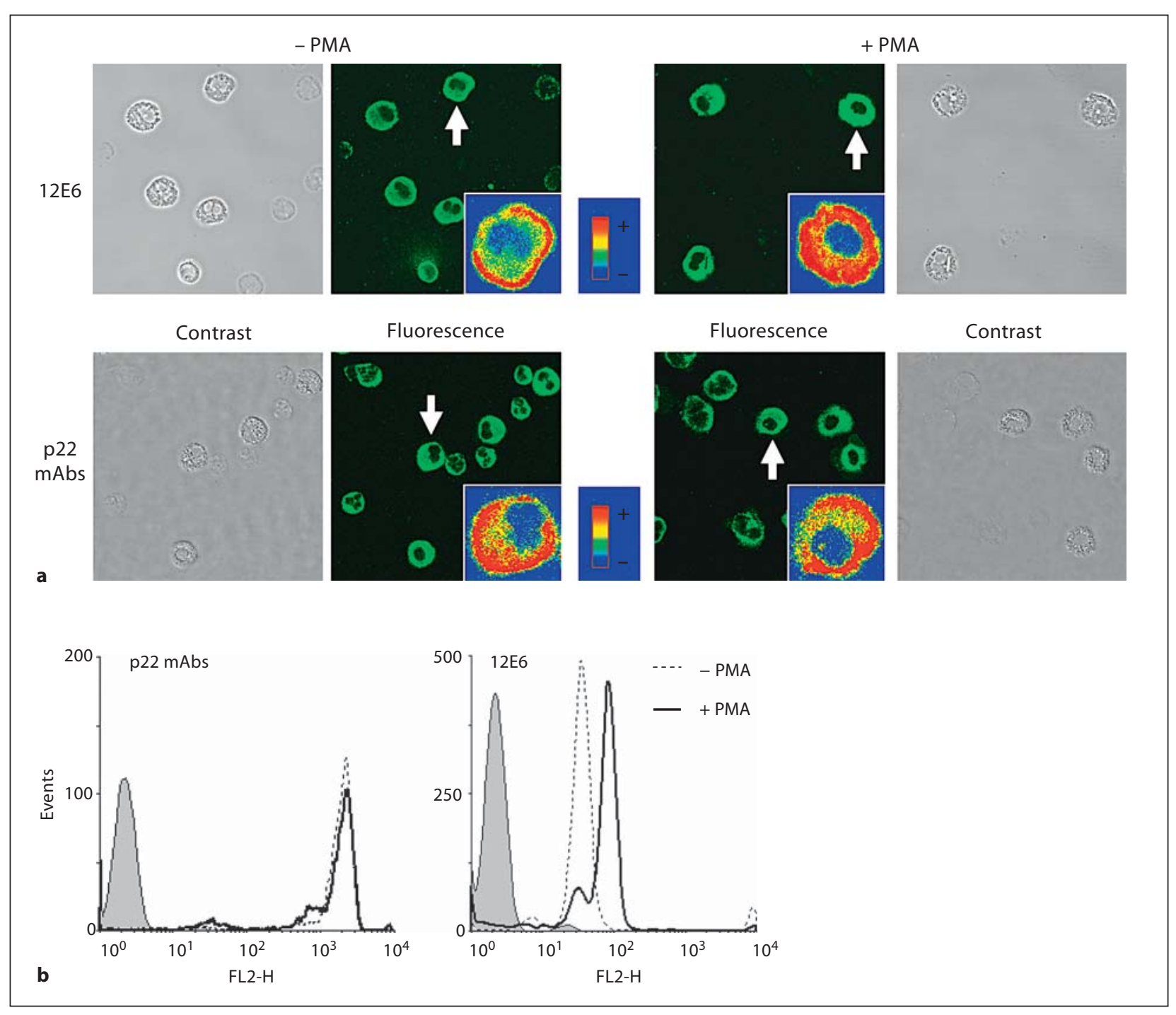

Fig. 8. Immunological analysis of cytochrome $b_{558}$ activation ex vivo. a Detection of p22-phox in resting and PMA-stimulated neutrophils by confocal microscopy. Neutrophils were incubated with PMA $(130 \mathrm{nM})$ or DMSO for $10 \mathrm{~min}$ at $37^{\circ} \mathrm{C}$. Resting and stimulated cells $\left(2 \times 10^{5}\right.$ cells) were then fixed, permeabilized and labeled with anti-p22-phox mAbs $(5 \mu \mathrm{g})$ for $1 \mathrm{~h}$ at room temperature as described in Materials and Methods. An Alexa Fluor 488 secondary antibody was used to detect the $\mathrm{mAb}$ binding. Inserts show typical cells (indicated by a white arrow) in false colors for the sake of comparison of fluorescence levels. Phase contrast, differential interference contrast and fluorescence images were re- corded. b Flow cytometry analysis of cytochrome $b_{558}$ in resting and PMA-stimulated neutrophils. Purified human neutrophils $\left(5 \times 10^{5}\right.$ cells) were stimulated (plain line) or not (dotted line) with $130 \mathrm{nM}$ PMA for $10 \mathrm{~min}$ at $37^{\circ} \mathrm{C}$, washed, fixed with $1 \%(\mathrm{w} / \mathrm{v})$ paraformaldehyde, permeabilized with $0.01 \%(\mathrm{w} / \mathrm{v})$ saponin and labeled with specific mAbs, $12 \mathrm{E} 6 \mathrm{mAb}$ or other p22-phox mAbs (17A2, 16G7, 16G6, 13D4 or 13C4; $5 \mu$ g; dotted and plain lines) or irrelevant $\mathrm{mAb}$ ( $5 \mu \mathrm{g}$; grey area) for $30 \mathrm{~min}$ on ice. The antibodylabeled cells were stained with PE-conjugated secondary antibody, and the fluorescence (FL2) was measured.

stimulated neutrophils. Moreover, the increased fluorescence in PMA-stimulated cells indicated that the binding of cytosolic factors to cy tochrome $b_{558}$ did not exclude the binding of mAb 12E6 to its epitope probably because of the epitope complexity. 
Fig. 9. Slot-blot analysis of mAb 12E6 binding to active and inactive cytochrome $b_{558}$ conformations. Duplicate samples of cytochrome $b_{558}(10 \mathrm{pmol})$ purified from resting (- PMA) or PMA-stimulated (+ PMA) neutrophils were adsorbed to the nitrocellulose under vacuum conditions. The membrane was then incubated with $\mathrm{mAb}$ 12E6. The immune complexes were detected by ECL. Histograms showed the relative densitometry analysis of the slot-blot $(100 \%$ corresponded to the densitometry obtained with cytochrome $b_{558}$ purified from resting cells). Results were expressed as the mean of densitometry values obtained after analysis of duplicate bands $\pm \mathrm{SD}$.

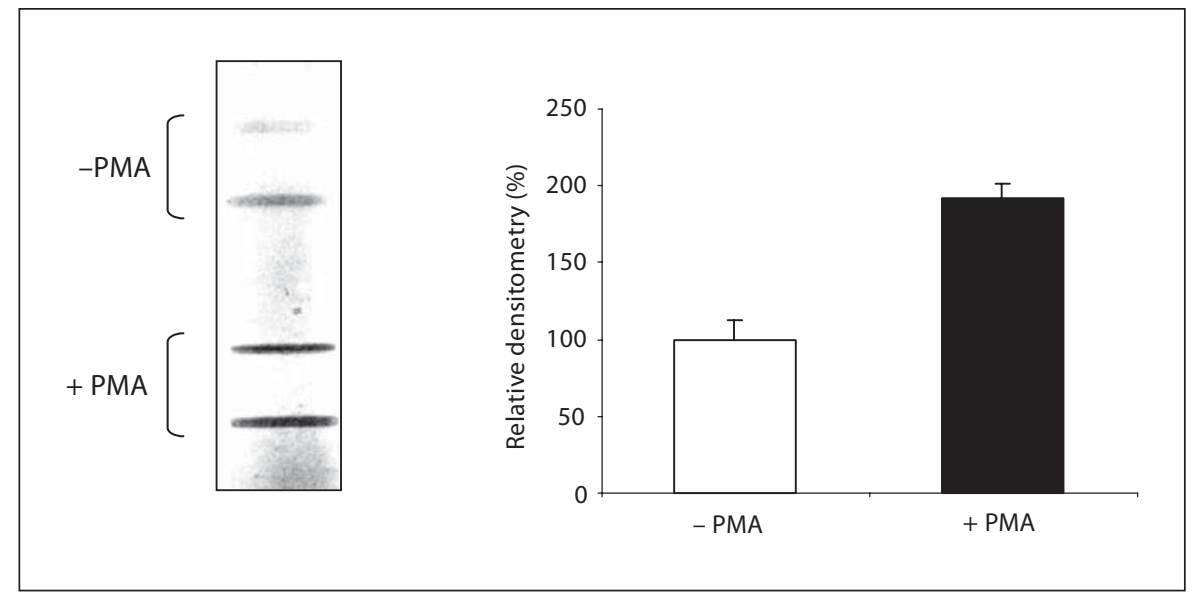

In order to confirm the conformational binding of $\mathrm{mAb} 12 \mathrm{E} 6$ to active cytochrome $b_{558}$, an in vitro slot-blot experiment was performed on native cytochrome $b_{558}$ purified either from resting or from stimulated neutrophils. In a previous work, we showed that cytochrome $b_{558}$ purified from PMA-stimulated cells displayed the capacity to form a constitutively active complex in the presence of cytosolic regulatory factors while cy tochrome $b_{558}$ purified from resting cells did not, indicating that cytochrome $b_{558}$ was pre-activated upon PMA stimulation, and that this conformation change was retained during the whole purification process [6]. In the present work, results clearly showed a strongly increased binding of $\mathrm{mAb} 12 \mathrm{E} 6$ to the same amount $(10 \mathrm{pmol})$ of cytochrome $b_{558}$ purified from PMA-stimulated neutrophils as compared to that observed with cytochrome $b_{558}$ isolated from resting cells (fig. 9, left panel). The slot-blot densitometry analysis indicated that the interaction between mAb 12E6 and cytochrome $b_{558}$ was doubled after stimulation with PMA (fig. 9, right panel).

\section{Discussion}

The present work describes 6 novel mAbs directed against an intracellular domain of p22-phox, the small subunit of the phagocyte cytochrome $b_{558}$. As no structural data are available for cytochrome $b_{558}$, mAbs are essential tools to get novel information about p22-phox membrane topology and regions involved in NADPH oxidase activation.

In this study, the $6 \mathrm{mAbs}$ recognized purified native cytochrome $b_{558}$ in $0.1 \%$ (w/v) Triton X-100 by ELISA, while only $5 \mathrm{mAbs}$ (mAbs 17A2, 16G7, 16G6, 13D4 and 13C4) were able to detect denatured p22-phox in membrane or in solubilized membrane fractions by immunoblotting. The inability of the $6 \mathrm{mAbs}$ to bind to intact neutrophils favors the intracellular localization of the epitopes, even if we could not completely rule out that the $\mathrm{mAbs}$ bind to extracellular regions that are masked on the cell surface until perturbation by permeabilization.

Phage display epitope mapping strongly suggested that $\mathrm{mAbs} 13 \mathrm{D} 4$ and $16 \mathrm{G} 7$ interact with the $\left({ }^{130} \mathrm{Q}-\mathrm{K}^{137}\right)$ and $\left({ }^{130} \mathrm{Q}-\mathrm{R}^{139}\right)$ regions of $\mathrm{p} 22$-phox, respectively.

For mAbs 17A2, 16G6 and 13C4, phage display results were not clear. The lack of recognition of the p22 $\left({ }^{1} \mathrm{M}\right.$ $\left.\mathrm{Q}^{143}\right)$-truncated form by the $3 \mathrm{mAbs}$ was consistent with detection of a cytoplasmic domain of p22-phox as shown by flow cytometry on permeabilized cells. Future refinements of FINDMAP with different substitution matrices and enhanced matching algorithms such as EPIMAP [27] may aid in the analysis of the clues to the structure of complex epitopes. Together, these results suggest that the target-region for mAbs 17A2, 16G6 and 13C4 is located in the C-terminal part of p22-phox that includes residues $\left({ }^{144} \mathrm{I}-\mathrm{V}^{195}\right)$.

Recent studies based on deletion mutagenesis experiments showed that $\mathrm{N}$ - and C-terminal regions of $\mathrm{p} 22$-phox contained specific determinants critical for cytochrome $b_{558}$ maturation and NADPH oxidase activation [28]. In particular, it was shown that deletion in the N-terminal (amino acids ${ }^{6} \mathrm{~W}-\mathrm{R}^{90}$ ) or the C-terminal portion (amino acids ${ }^{131} \mathrm{~W}-\mathrm{V}^{195}$ ) leads to a defect in Nox 2 maturation and thus in NADPH oxidase activity [28]. Interestingly, deletion of the polyproline-containing region $\left({ }^{142} \mathrm{P}-\mathrm{V}^{195}\right)$ did not influence cytochrome $b_{558}$ maturation but resulted in 


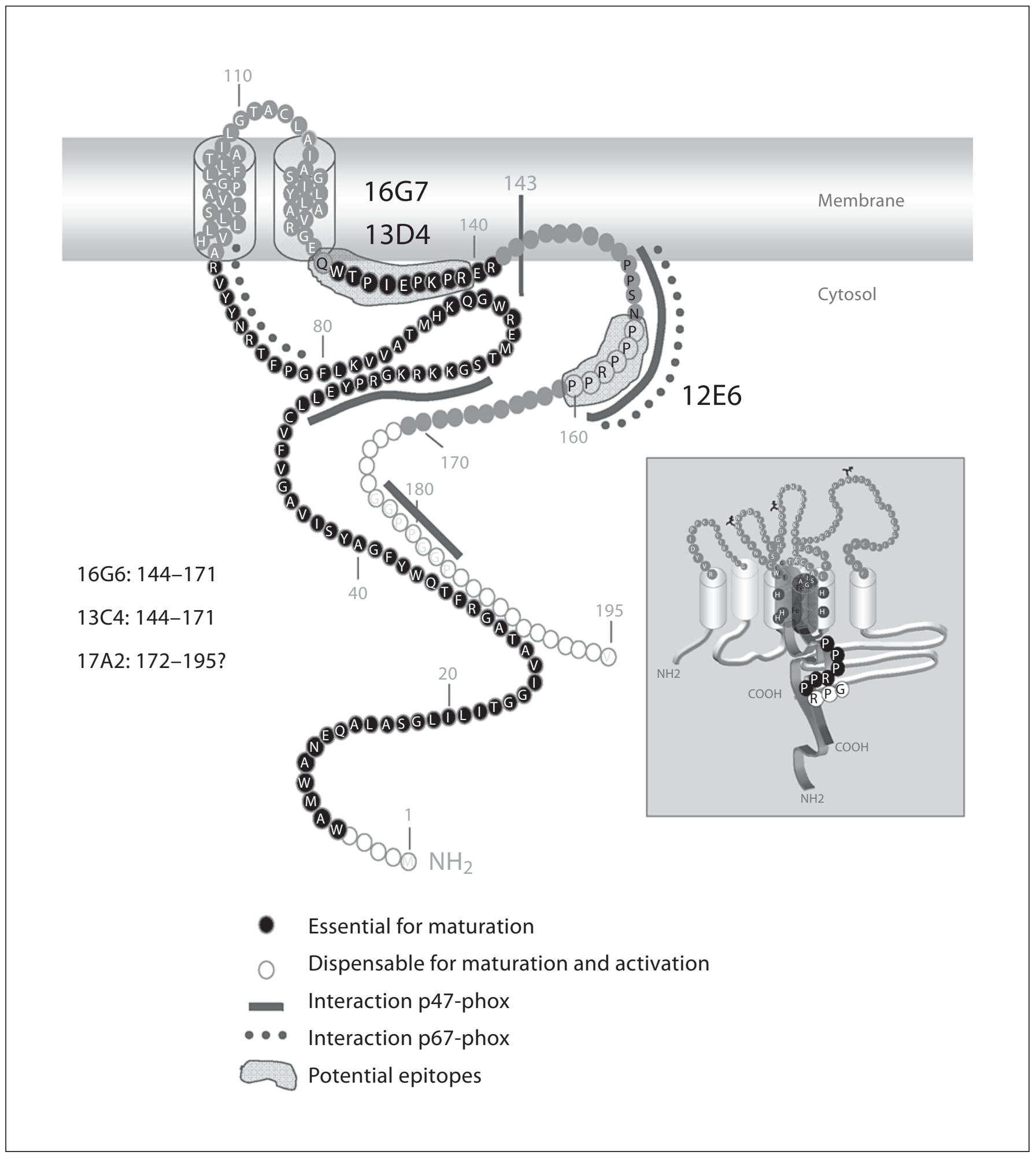

Fig. 10. Topological model of p22-phox. The model highlights 2 transmembrane domains, regions containing amino acids shown to be essential or dispensable for cytochrome $b_{558}$ maturation and activation [27] as well as regions involved in interactions with p47-phox and p67-phox. Epitope regions for novel mAbs resulting from data combining phage display analysis and p22-phox truncated forms investigation are depicted in this model. The insert shows potential epitope for mAb 12E6 shared by p22-phox $\left({ }^{155} \mathrm{PPPRPP}^{160}\right)$ and gp91-phox $\left({ }^{557} \mathrm{GPR}^{559}\right)$. 
the absence of NADPH oxidase activity [28]. These results suggest that the amino acids $\left({ }^{131} \mathrm{~W}-\mathrm{R}^{141}\right)$ are essential for Nox 2 stabilization and maturation (fig. 10). The mAb NS2 that was earlier described to interact with the $\left({ }^{131} \mathrm{~W}-\mathrm{R}^{139}\right)$ sequence of p22-phox was unable to immunoprecipitate detergent-solubilized cytochrome $b_{558}$ [13]. In our study, $\mathrm{mAbs} 13 \mathrm{D} 4$ and $16 \mathrm{G} 7$ that recognize a similar region of p22-phox $\left({ }^{130} \mathrm{Q}-\mathrm{K}^{137}\right.$ for $\mathrm{mAb} 13 \mathrm{D} 4$ and ${ }^{130} \mathrm{Q}-\mathrm{R}^{139}$ for $\mathrm{mAb}$ 16G7) were shown to immunoprecipitate detergent-solubilized cytochrome $b_{558}$, suggesting exclusive properties of both mAbs 13D4 and 16G7 in comparison to mAb NS2. In regard to the importance of the target epitope, these mAbs might be useful for cellular analysis of cytochrome $b_{558}$ maturation by evaluating their effect on p22-phox/ gp91-phox heterodimer formation. As previously described for mAb NS2 [13], both mAbs 13D4 and 16G7 did not influence the NADPH oxidase activity, suggesting that the region $\left({ }^{130} \mathrm{Q}-\mathrm{R}^{139}\right)$ of $\mathrm{p} 22$-phox is not involved in enzyme activation or activity.

MAb 12E6 displays interesting properties. It is unable to bind denatured cytochrome $b_{558}$, arguing in favor of a conformational target epitope easily lost or masked by mild detergent. Moreover, data obtained by confocal microscopy and flow cytometry demonstrate that $\mathrm{mAb}$ 12E6 binds activated neutrophils more strongly than resting cells. This effect is also observed in vitro on cytochrome $b_{558}$ purified from PMA-stimulated cells, suggesting a conformational epitope which is unmasked during NADPH oxidase activation. Phage display analysis performed with $\mathrm{mAb} 12 \mathrm{E} 6$ indicates a potential antigen-determinant in the region $\left({ }^{152} \mathrm{P}-\mathrm{P}^{159}\right)$ of $\mathrm{p} 22$-phox, the region containing a polyproline domain required for the interaction with p47-phox and p67-phox upon activation (fig. 10) $[14,15]$. The polyproline region is probably inaccessible in the cytochrome $b_{558}$ resting state in order to avoid uncontrolled NADPH oxidase activation. Upon cytochrome $b_{558}$ activation, the $\mathrm{p} 22$-phox polyproline region may change its conformation leading to a better accessibility of cytosolic factors to the domain. This hypothesis was confirmed by the inhibitory effect of $\mathrm{mAb}$ $12 \mathrm{E} 6$ on the NADPH oxidase activity reconstituted in vitro in the presence of neutrophil membrane and cytosol. Moreover, the analysis of the phage peptide sequences using FINDMAP revealed a potential epitope shared between p22-phox $\left({ }^{155} \mathrm{P}-\mathrm{P}^{160}\right.$ residues) and the C-terminal part of gp91-phox ( ${ }^{557} \mathrm{G}-\mathrm{R}^{559}$ residues). Although such an assignment is highly speculative and requires confirmation, such complexity could explain the epitope lability in SDS and the nonionic detergent octyl glucoside. If indeed the epitope is shared by gp91-phox and p22-phox, $\mathrm{mAb}$
12E6 will be useful to study interactions between cytochrome $b_{558}$ subunits during protein maturation and enzyme activation processes.

For mAbs 17A2, 16G6 and 13C4, the epitope region was not clearly determined. However, immunoblots performed on the p22 $\left({ }^{1} \mathrm{M}-\mathrm{Q}^{143}\right)$-truncated form suggested that their target-epitope was located in the cytosolic Cterminal 52 residues $\left({ }^{144} \mathrm{I}-\mathrm{V}^{195}\right)$ of p22-phox. Deletion mutagenesis performed on p22-phox previously showed that the $\mathrm{N}$-terminal residues $\left({ }^{1} \mathrm{M}-{ }^{5} \mathrm{E}\right)$ and the $\mathrm{C}$-terminal residues $\left({ }^{172} \mathrm{~A}-\mathrm{V}^{195}\right)$ are not necessary for cytochrome $b_{558}$ maturation and NADPH oxidase activity (fig. 10) [28]. Pre-incubation of neutrophil membranes with either $\mathrm{mAb} 16 \mathrm{G} 6$ or mAb 13C4 leads to a complete inhibition of the reconstituted NADPH oxidase activity, indicating that they interact with a region important for NADPH oxidase activation, located between amino acids ${ }^{144}$ I and ${ }^{171} \mathrm{E}$. In contrast, $\mathrm{mAb} 17 \mathrm{~A} 2$ has no effect on the NADPH oxidase activity reconstituted in vitro, suggesting a potential interaction site in the C-terminal part of p22-phox dispensable for activation (after the polyproline motif) $\left({ }^{161} \mathrm{~A}-\mathrm{V}^{195}\right)$.

In conclusion, among the 6 new p22-phox mAbs described in this study, 2 (13D4 and 16G7) recognize a region required for cytochrome $b_{558}$ maturation $\left({ }^{130} \mathrm{Q}-\mathrm{R}^{139}\right)$. Three mAbs, 16G6, 13C4 and 17A2, bind an epitope localized in the C-terminal region $\left({ }^{144} \mathrm{IV}^{195}\right)$ but they display specific properties: mAbs $16 \mathrm{G} 6$ and $13 \mathrm{C} 4$, but not $\mathrm{mAb} 17 \mathrm{~A} 2$, interact with a region involved in $\mathrm{NADPH}$ oxidase activation. According to data resulting from deletion mutagenesis performed on p22-phox [28], the Cterminal part of p22-phox $\left({ }^{172} \mathrm{~A}-\mathrm{V}^{195}\right)$ is not necessary for enzyme activity, suggesting that epitopes for mAbs 16G6 and $13 \mathrm{C} 4$ are located in the $\left.{ }^{144} \mathrm{I}-\mathrm{E}^{171}\right)$ part of p22-phox. The last $\mathrm{mAb}$ (12E6) recognizes a conformational epitope localized partially in the polyproline region of p22-phox. This $\mathrm{mAb}$ is unique as this is the first one described to detect this p22-phox domain. Our results lend support to the speculative view that this region may be part of a complex epitope shared between gp91-phox and p22phox that may be produced during the activation process. However, there is as yet no confirming evidence to support this structural interpretation.

As p22-phox is an essential partner for novel Nox (Nox1, Nox3 and Nox4), these mAbs represent a valuable set of probes to investigate maturation and activation processes of NADPH oxidases. 


\section{Acknowledgements}

We thank Dr. J. C. Renversez (DBI, CHU de Grenoble) for isotyping the monoclonal antibodies.

This work was supported by grants from the Ministère de l'Enseignement supérieur de la Recherche et Technologie, Paris, the UFR de Médecine, Université Joseph Fourier, Grenoble, the
Région Rhône Alpes, programme Emergence 2003, the Groupement des Entreprises Françaises dans la lutte contre le Cancer, délégation de Grenoble, the Fondation pour la Recherche Médicale, Isère, the Délégation Régionale de la Recherche Clinique, CHU Grenoble and the French association La Ligue Nationale contre le Cancer. A.J.J. is supported by United States Public Health Service grants R56AI22735 and 5RO1AI26711.

\section{References}

${ }_{1}$ Vignais $\mathrm{P}$ V: The superoxide-generating NADPH oxidase: structural aspects and activation mechanism. Cell Mol Life Sci 2002; 59:1428-1459.

$\checkmark 2$ Nauseef W: Nox enzymes in immune cells. Semin Immunopathol 2008;30:195-208.

$\checkmark 3$ Cross AR, Segal AW: The NADPH oxidase of professional phagocytes-prototype of the NOX electron transport chain systems. Biochim Biophys Acta 2004;1657:1-22.

$\checkmark 4$ Bokoch GM, Zhao T: Regulation of the phagocyte NADPH oxidase by Rac GTPase. Antioxid Redox Signal 2006;8:1533-1548.

$\checkmark 5$ Paclet MH, Coleman AW, Vergnaud S, Morel F: P67-phox-mediated NADPH oxidase assembly: imaging of cytochrome $b_{558}$ liposomes by atomic force microscopy. Biochemistry 2000;39:9302-9310.

-6 Paclet MH, Berthier S, Kuhn L, Garin J, Morel F: Regulation of phagocyte NADPH oxidase activity: identification of two cytochrome $b_{558}$ activation states. FASEB J 2007; 21:1244-1255.

7 Heyworth PG, Cross AR, Curnutte JT: Chronic granulomatous disease. Curr Opin Immunol 2003;15:578-584.

8 Morel F: Molecular aspects of chronic granulomatous disease. Bull Acad Natl Med 2007; 191:377-390.

$\checkmark 9$ Cross AR, Segal AW: The NADPH oxidase of professional phagocytes-prototype of the NOX electron transport chain systems. Biochim Biophys Acta 2004;1657:1-22.

$\checkmark 10$ DeLeo FR, Burritt JB, Yu L, Jesaitis AJ, Dinauer MC, Nauseef WM: Processing and maturation of flavocytochrome $b_{558}$ include incorporation of heme as a prerequisite for heterodimer assembly. J Biol Chem 2000; 275:13986-13993.

- 11 Ambasta RK, Kumar P, Griendling KK, Schmidt HHHW, Busse R, Brandes RP: Direct interaction of the novel nox proteins with p22phox is required for the formation of a functionnally active NADPH oxidase. J Biol Chem 2004;279:45935-45941.

- 12 Ueno N, Takeya R, Miyano K, Kikuchi H, Sumimoto H: The NADPH oxidase Nox3 constitutively produces superoxide in a p22phox-dependent manner: its regulation by oxidase organizers and activators. J Biol Chem 2005;280:23328-23339.
13 Taylor RM, Burritt JB, Baniulis D, Foubert TR, Lord CI, Dinauer MC, Parkos CA, Jesaitis AJ: Site-specific inhibitors of NADPH oxidase activity and structural probes of flavocytochrome $b$ : characterization of six monoclonal antibodies to the p22-phox subunit. J Immunol 2004;173:7349-7357.

14 Sumimoto H, Kage Y, Nunoi H, Sasaki H, Nose T, Fukumaki Y, Ohno M, Minakami S, Takeshige K: Role of Src homology 3 domains in assembly and activation of the phagocyte NADPH oxidase. Proc Natl Acad Sci USA 1994;91:5345-5349.

15 Dahan I, Issaeva I, Gorzalczany Y, Sigal N, Hirshberg M, Pick E: Mapping of functional domains in the p22-phox subunit of flavocytochrome $b_{558}$ participating in the assembly of the NADPH oxidase complex by 'peptide walking’. J Biol Chem 2002;277:8421-8432.

16 Berthier S, Paclet MH, Lerouge S, Roux F, Vergnaud S, Coleman AW, Morel F: Changing the conformation state of cytochrome $b_{558}$ initiates NADPH oxidase activation: MRP8/MRP14 regulation. J Biol Chem 2003; 278:25499-25508.

17 Campion Y, Paclet MH, Jesaitis AJ, Marques B, Grichine A, Berthier S, Lenormand JL, Lardy B, Stasia MJ and Morel F: New insights into the membrane topology of the phagocyte NADPH oxidase: characterization of an anti-gp91-phox conformational monoclonal antibody. Biochimie 2007;89:1145-1158.

-18 Batot G, Martel C, Capdeville N, Wientjes F, Morel F: Characterization of neutrophils NADPH oxidase activity reconstituted in a cell-free assay using specific monoclonal antibodies raised against cytochrome $b_{558}$. Eur J Biochem 1995;234:208-215.

19 Paclet MH, Henderson LM, Campion Y, Morel F, Dagher MC: Localization of Nox2 Nterminus using polyclonal antipeptide antibodies. Biochem J 2004;382:981-986.
20 Paclet MH, Coleman AW, Burritt J, Morel F: NADPH oxidase of Epstein-Barr-virus immortalized B lymphocytes: effect of cytochrome $b_{558}$ glycosylation. Eur J Biochem 2001;268:5197-5208.

21 Vergnaud S, Paclet MH, El Benna J, Pocidalo MA, Morel F: Complementation of NADPH oxidase in p67-phox-deficient CGD patients p67-phox/p40-phox interaction. Eur J Biochem 2000;267:1059-1067.

22 Burritt JB, Bond CW, Doss KW, Jesaitis AJ: Filamentous phage display of oligopeptide libraries. Anal Biochem 1996;238:1-13.

23 Burritt JB, Quinn MT, Jutila MA, Bond CW, Jesaitis AJ: Topological mapping of neutrophils cytochrome $b$ epitopes with phage-display libraries. J Biol Chem 1995;270:1697416980.

24 Mumey BM, Bailey BW, Kirkpatrick B, Jesaitis AJ, Angel T, Dratz EA: A new method for mapping discontinuous antibody epitopes to reveal structural features of proteins. J Comput Biol 2003;10:555-567.

25 Laemmli UK: Cleavage of structural proteins during the assembly of the head of bacteriophage T4. Nature 1970;227:680-685.

26 Towbin H, Staehelin T, Gordon J: Electrophoretic transfer of proteins from polyacrylamide gels to nitrocellulose sheets: procedure and some applications. Proc Natl Acad Sci USA 1979;76:4350-4354.

27 Mumey BM, Ohler N, Angel T, Jesaitis AJ, Dratz EA: Filtering epitope alignments to improve protein surface prediction; in Lecture Notes in Computer Science. Frontiers of High Performance Computing and Networking - ISPA. Berlin/Heidelberg, Springer, 2006, 648-657.

28 Zhu Y, Marchal CC, Casbon AJ, Stull N, Lohneysen KV, Knaus UG, Jesaitis AJ, McCormick S, Nauseef WM, Dinauer MC: Deletion mutagenesis of p22-phox subunit of flavocytochrome $b_{558}$ : identification of regions critical for gp91-phox maturation and NADPH oxidase activity. J Biol Chem 2006;281: 30336-30346. 